Research Article

\title{
Clinical and Laboratory Findings of 12 Children with Invasive Meningococcal Disease in Pediatric Intensive Care Unit
}

\author{
Eylem Kiral ${ }^{1}{ }^{1}$ and Ayse Filiz Yetimakman ${ }^{2}{ }^{2}$ \\ ${ }^{1}$ Department of Pediatric Intensive Care, Eskisehir Osmangazi University Faculty of Medicine, Eskisehir 26040, Turkey \\ ${ }^{2}$ Department of Pediatric Intensive Care, Kocaeli University Faculty of Medicine, Umuttepe, Izmit 41001, Turkey \\ Correspondence should be addressed to Eylem Kiral; dr_eylem@hotmail.com
}

Received 22 April 2021; Revised 28 June 2021; Accepted 29 August 2021; Published 5 September 2021

Academic Editor: Mohammad-Salar Hosseini

Copyright ( $) 2021$ Eylem Kiral and Ayse Filiz Yetimakman. This is an open access article distributed under the Creative Commons Attribution License, which permits unrestricted use, distribution, and reproduction in any medium, provided the original work is properly cited.

\begin{abstract}
Introduction. Invasive meningococcal disease (IMD) is a serious infectious disease requiring stay in a pediatric intensive care unit (PICU) that continues to be associated with high morbidity and mortality rates. Prompt recognition, early antibiotic therapy, and aggressive supportive therapies can reduce mortality. We aimed to assess the clinical and laboratory characteristics of children with IMD. Patients and Methods. We retrospectively evaluated the medical records of 12 children with IMD requiring PICU stay between January 2018 and July 2019. Results. We followed up 12 patients (five girls and seven boys, 5-168 months of age, and four below one year of age) with IMD (nine patients have meningococcemia with meningitis, and three patients have meningococcemia) in PICU. All children were previously healthy and have not received meningococcal vaccines. Their pediatric risk of mortality (PRISM) scores varies between 5 and 37, four of the patients required mechanical ventilation, and the predicted mortality was 39\% at admission. Seven patients had catecholamine refractory septic shock and disseminated intravascular coagulation (DIC). Three of the patients required extracorporeal treatment. The predominant serogroup is Men B (5/12). The mortality rate was $16.6 \%$ with early use of antibiotics, fluids, and other interventions. Conclusion. Mortality related to IMD is higher among children with severe meningococcemia despite early interventions in PICU. Routine use of meningococcal vaccines during childhood would be a better strategy for controlling IMD in both developing and developed countries.
\end{abstract}

\section{Introduction}

Invasive meningococcal disease (IMD) due to Neisseria meningitidis is an important cause of morbidity and mortality in children worldwide [1]. N. meningitides are classified into 12 serogroups according to the antigenic variability of their capsules, and among them, serogroups $\mathrm{A}, \mathrm{B}, \mathrm{C}, \mathrm{Y}, \mathrm{W}$, and $\mathrm{X}$ are clinically important $[1,2]$. The epidemiology of serogroups changes over the years, and patient data on clinical presentation and laboratory workup will be helpful for diagnosis and treatment $[1,2]$. A majority of the patients are below five years of age, and secondary peaks have been reported among adolescents and young adults [3]. While there are some risk factors associated with IMD, for example, travel to endemic regions, complement deficiency, splenectomy, HIV infection, or eculizumab use, the majority of the patients $(>95 \%)$ with IMD were previously healthy $[1,2,4]$.

Meningococcemia is a sudden onset, fulminant contagious disease requiring stay in an intensive care unit [5]. Despite the developments in supportive therapies and intensive care treatments, there is a high rate of mortality with IMD $[1,2]$. Within the last 20 years, case fatality rates (CFR) are reported between 9 and $12 \%$, which varies according to serogroups and age, and CFR might increase in cases with meningococcemia, infections due to hyperinvasive clones, and in older age groups [6]. Herein, we report the clinical and laboratory findings of children with IMD requiring stay in a pediatric intensive care unit. 


\section{Patients and Methods}

Patients who were admitted to the pediatric intensive care unit (PICU) of Sanliurfa Training and Research Hospital between January 2018 and June 2019 with a diagnosis of IMD were included. Diagnosis of IMD was confirmed by the detection of $N$. meningitides with culture and/or the polymerase chain reaction (PCR) method in cerebrospinal fluid (CSF) and/or blood samples. Patient's age, gender, presence of underlying disease, and vaccination status were recorded. Complete blood count, peripheral blood smears, serum $\mathrm{C}$ reactive protein (CRP) and procalcitonin levels, arterial blood gas analysis, phrothrombin time (PT), activated partial thromboplastin time (aPTT), fibrinogen, D-dimer, and blood culture results were noted from medical records. CSF workup results were recorded for patients who were eligible for a lumbar puncture. Patients were diagnosed as disseminated intravascular coagulation (DIC) if they met the criteria for at least one of the following: platelet count $<150000 / \mathrm{mm}^{3}$, fibrinogen level $<250 \mathrm{mg} / \mathrm{dL}$, D-dimer level $>500 \mathrm{U} / \mathrm{L}$, long PT, and PTT $(>13.2$ seconds and $>31 \mathrm{sec}-$ onds, respectively) [7]. Septic shock was diagnosed with the criteria defined in "Surviving Sepsis Campaign: International Guidelines for the Management of Severe Sepsis and Septic shock: 2016" [7]. Pediatric risk of mortality (PRISM) scores were recorded for all patients with the worst clinical and laboratory data within the first 24 hours. Supportive extracorporeal therapies as renal replacement therapy and plasma exchange therapy were recorded. Vasoactive-inotropic score (VIS) was calculated with the formula: dopamine dose $(\mu \mathrm{g} / \mathrm{kg} / \mathrm{min})+$ dobutamine dose $(\mu \mathrm{g} / \mathrm{kg} /$ $\min )+100 \times$ adrenaline dose $(\mu \mathrm{g} / \quad \mathrm{kg} /$ $\min )+100 \times$ noradrenaline dose $(\mu \mathrm{g} / \mathrm{kg} /$ $\min )+10 \times$ milrinone dose $(\mu \mathrm{g} / \mathrm{kg} /$ $\min )+10,000 \times$ vasopressin dose $(\mathrm{U} / \mathrm{kg} / \mathrm{min})$. Prognosis of the patients has been classified as "died" or "discharged."

\section{Results}

Twelve children (five girls and seven boys) aged between 5 and 168 months with IMD were enrolled. All patients were reported to healthcare authorities, and all of the persons with a history of close contact were started on prophylactic treatment by the Local Public Health Department. The clinical, demographical, and laboratory findings of the children are summarized in Tables 1 and 2 .

Three patients were diagnosed with meningococcemia (cases 5, 6, and 12), while the remaining nine were diagnosed with meningococcemia and meningitis. Four of the patients in our study were younger than one year of age $(33.3 \%)$, three were aged between 1 to 5 years, and five (41.6\%) were older than five years. One child was a member of a Syrian refugee family. None of the patients had been previously vaccinated with meningococcal vaccines. Two of the patients (cases 4 and 10) had no history of other childhood routine immunizations.

PRISM scores vary between 5 and 37, and predicted mortality according to PRISM scores was between 1.7 and 94.2\% (Table 2). The highest predicted mortality according to PRISM was for cases 1,2 , and $4(88.2,85.2$, and $94.2 \%$, respectively); cases 1 and 4 died (Table 2 ).

Fever was the common presenting symptom for all the patients. The period time between the onset of symptoms and presentation varied between 12 and 72 hours, and all of the patients were referred because of fever and petechiae/ purpuric lesions. Cases 3, 6, 11, and 12 presented with petechiae and purpuric lesions on extremities, case 7 had purpuric lesions only in the anal region, and the rest of the cases had lesions disseminated over the entire body.

Five out of 12 patients had IMD due to serogroup B, and one case was due to serogroup W. All of the patients were given fluid resuscitation and antibiotic treatment of ceftriaxone $(100 \mathrm{mg} / \mathrm{kg} /$ day 2 times or cefotaxime $200 \mathrm{mg} / \mathrm{kg} /$ day 4 times). The first dose of antibiotic treatment was given at the first hour of admission to the pediatric emergency care unit. Vancomycin was empirically given to case 4 due to suspected toxic shock syndrome until the causative bacteria had been identified (Table 2). Seven patients had signs of septic shock and DIC (cases 1, 2, 3, 4, 7, 9, and 12). Four cases were intubated and treated by mechanical ventilation support (cases 1, 4, 7, and 9). Cases 1 and 4 had continuous hemodiafiltration therapy, and case 9 had therapeutic plasma exchange (PLEX). Supportive therapies are summarized in Table 2 for these 12 patients who were treated with the diagnosis of IMD. All of the cases had an echocardiographic evaluation, and ejection fraction was found to be lower than normal in cases 1, 2, 4, and 9. Cases 1 and 4 went into catecholamine-resistant shock and did not survive despite treatment with stress doses of hydrocortisone, adrenaline, dopamine, and milrinone infusions. Case 1 was intubated with respiratory distress after seizures on day one of PICU admission and had diabetes insipidus within the next 48 hours. The patient died on day 8 after admission. Case 4, who was born as a twin, had growth retardation (body weight was $<3^{\text {rd }}$ percentile) and a history of being treated for a symptom of fever within the previous two days. The patient presented with a history of extension posturing and convulsions at home, and purpuric lesions appeared within two hours of admittance. Purpura fulminans developed within hours, and the patient died on the fifth day of PICU admission.

\section{Discussion}

IMD continues to be an important public health issue that results in high rates of mortality and morbidity in childhood. Beginning treatment promptly and extensive therapy protocols are life-saving in these critically ill patients [1, 2, 8, 9]. In this study, we followed up 12 children with IMD in PICU, and two of these patients did not survive despite being treated early. Early antibiotic treatment (first hours of admission) is a crucial step in the treatment of meningococcemia. The targeted therapy approach should include not only starting antibiotic treatment immediately but also early recognition and treatment of complications of the infection such as shock $[7,8]$. In our case series, four cases with catecholamineresistant septic shock (VIS scores of $80,85,55$, and 70 , 
TABle 1: Demographical findings, glasgow coma scale, and laboratory findings of 12 children with IMD.

\begin{tabular}{|c|c|c|c|c|c|c|c|c|c|c|c|c|}
\hline $\begin{array}{l}\text { Case } \\
\text { number }\end{array}$ & $\begin{array}{c}\text { Age } \\
\text { (months) }\end{array}$ & Gender & GCS & $\begin{array}{l}\text { WBC } \\
\left(\mathrm{mm}^{3}\right)\end{array}$ & $\begin{array}{c}\text { Platelet } \\
\left(\mathrm{mm}^{3}\right)\end{array}$ & $\begin{array}{c}\text { Lactate } \\
(\mathrm{mmol} / \mathrm{L})\end{array}$ & $\begin{array}{c}\text { CRP } \\
(\mathrm{mg} / \mathrm{dl})\end{array}$ & $\begin{array}{c}\text { PCT } \\
\text { (ng/mL) }\end{array}$ & Echocardiography & $\begin{array}{l}\text { Severity } \\
\text { of sepsis }\end{array}$ & VIS & $\begin{array}{c}\mathrm{Nm} \\
\text { Serogroup }\end{array}$ \\
\hline 1 & 72 & G & 3 & 33,290 & 20,000 & 8.3 & 170 & 100 & EF $40 \%$ & MOSF & 80 & $\mathrm{~W}$ \\
\hline 2 & 11 & G & 7 & 27,000 & 29,000 & 5.3 & 469 & 100 & Normal & $\begin{array}{l}\text { Septic } \\
\text { shock }\end{array}$ & 30 & B \\
\hline 3 & 84 & B & 7 & 30,000 & 80,000 & 3 & 130 & 100 & Normal & $\begin{array}{l}\text { Septic } \\
\text { shock }\end{array}$ & - & - \\
\hline 4 & 12 & B & 3 & 25,000 & 21,000 & 24 & 332 & 100 & EF $30 \%$ & MOSF & 85 & $\mathrm{~B}$ \\
\hline 5 & 62 & G & 10 & 10,300 & 73,800 & 2.8 & 69 & 40 & Normal & Sepsis & - & - \\
\hline 6 & 60 & $\mathrm{~B}$ & 7 & 18,000 & 47,000 & 3.6 & 86 & 45 & Normal & Sepsis & - & - \\
\hline 7 & 26 & $\mathrm{~B}$ & 7 & 33,000 & 30,000 & 3.8 & 157 & 100 & EF $50 \%$ & $\begin{array}{l}\text { Septic } \\
\text { shock }\end{array}$ & 55 & B \\
\hline 8 & 56 & B & 12 & 21,500 & 65,000 & 2 & 76 & 80 & Normal & Sepsis & - & B \\
\hline 9 & 168 & B & 9 & 35,690 & 12,000 & 5.9 & 180 & 100 & EF $42 \%$ & TAMOF & 70 & - \\
\hline 10 & 6 & G & 13 & 19,100 & 66,700 & 1.5 & 82 & 55 & Normal & Sepsis & - & B \\
\hline 11 & 70 & G & 11 & 23,000 & 98,000 & 1.7 & 74 & 85 & Normal & Sepsis & - & - \\
\hline 12 & 11 & B & 11 & 13,500 & 74,000 & 2.0 & 70 & 50 & Normal & $\begin{array}{l}\text { Septic } \\
\text { shock }\end{array}$ & - & - \\
\hline
\end{tabular}

PRISM: pediatric risk of mortality; GCS: Glasgow Coma Scale; PICU: pediatric intensive care unit; WBC: white blood cell; CRP: C-reactive protein, PCT: procalcitonin; VIS: vasoactive-inotropic score; G: girl B: boy.

TABle 2: Clinical interventions in PICU, PRISM score, predicted mortality, and prognosis of 12 children with IMD.

\begin{tabular}{|c|c|c|c|c|c|c|c|c|c|c|}
\hline $\begin{array}{l}\text { Case } \\
\text { number }\end{array}$ & Antibiotic & $\begin{array}{l}\text { Fluid resuscitation at } \\
\text { admission } 20 \mathrm{mg} / \mathrm{kg} \\
\text { in } 20 \text { minutes (times) }\end{array}$ & $\begin{array}{l}\text { FFP } \\
\text { Tran }\end{array}$ & $\begin{array}{l}\text { Platelet } \\
\text { nsfusion }\end{array}$ & ECT & $\begin{array}{l}\text { Mechanical } \\
\text { ventilation }\end{array}$ & $\begin{array}{l}\text { PRISM } \\
\text { score }\end{array}$ & $\begin{array}{l}\text { Predicted } \\
(\%)\end{array}$ & $\begin{array}{l}\text { Length of } \\
\text { PICU stay } \\
\text { (days) }\end{array}$ & Prognosis \\
\hline 1 & Cefotaxime & 2 & 5 & 4 & CVVHDF & MV & 34 & 88.2 & 8 & Died \\
\hline 2 & Cefotaxime & 2 & 2 & 2 & - & - & 32 & 85.2 & 7 & Discharged \\
\hline 3 & Cefotaxime & 2 & & 2 & - & & 20 & 25.7 & 5 & Discharged \\
\hline 4 & $\begin{array}{l}\text { Cefotaxime, } \\
\text { vancomycin }\end{array}$ & 2 & 4 & 4 & CVVHDF & MV & 37 & 94.2 & 5 & Died \\
\hline 5 & Cefotaxime & 2 & 3 & - & - & - & 15 & 11.7 & 4 & Discharged \\
\hline 6 & Cefotaxime & 2 & 3 & - & - & - & 13 & 8.2 & 3 & Discharged \\
\hline 7 & Cefotaxime & 2 & 2 & 2 & - & MV & 25 & 56.7 & 3 & Discharged \\
\hline 8 & Ceftriaxone & 1 & & - & - & - & 5 & 1.7 & 3 & Discharged \\
\hline 9 & Cefotaxime & 3 & 2 & 3 & PLEX & MV & 30 & 64.2 & 9 & Discharged \\
\hline 10 & Ceftriaxone & 1 & & - & - & - & 11 & 7.3 & 4 & Discharged \\
\hline 11 & Ceftriaxone & 1 & & - & - & - & 12 & 6.4 & 4 & Discharged \\
\hline 12 & Cefotaxime & 2 & 3 & 2 & - & - & 17 & 21.1 & 4 & Discharged \\
\hline
\end{tabular}

FFP: fresh frozen plasma, ECT: extracorporeal treatment; CVVHDF: continuous veno-venous hemodiafiltration, PLEX: therapeutic plasma exchange; PRISM: pediatric risk of mortality; PICU: pediatric intensive care unit.

respectively), required stress doses of hydrocortisone. Stress dosages of hydrocortisone are indicated if the shock is exacerbated by adrenal insufficiency [8]. Dialysis or hemofiltration may be needed to compensate for kidney injury and to reduce the massive edema from fluid resuscitation [8]. Continuous veno-venous hemodiafiltration was performed in case 1 due to acute kidney injury, anuria, and fluid overload exceeding $15 \%$ for two days, and in case 4 due to cytokine removal for one day. We preferred this renal replacement modality because the blood pressure of our patients was not stable. We used PLEX with fresh frozen plasma four times in case 9 with sepsis-associated organ dysfunction with thrombocytopenia-associated multiple organ failure. We observed diabetes insipidus as an early period complication in one case with meningococcal meningitis. Meningococcal meningitis may be complicated by raised intracranial pressure or the syndrome of inappropriate antidiuretic hormone secretion [10]. Despite all treatment modalities, the mortality rate was $16.6 \%$ in PICU. In our study, two patients, who had laboratory and clinical findings of multiorgan failure, died. The rate of mortality was higher than the classic $10 \%$ mortality rate $[6,8]$. We enrolled only children with severe conditions requiring PICU, and the predicted mortality regarding pediatric risk of mortality at admission was higher than $20 \%$ in seven out of 12 cases.

Recognition of symptoms is of critical importance in diagnosing IMD. IMD should be in the differential diagnosis in every pediatric case presenting with fever and petechiae [11]. Definitive diagnosis is confirmed by cultures of blood and CSF. Also, bacteria can be isolated from biopsies of skin lesions. In recent years, detecting bacterial DNA by PCR has 
become an important method of diagnosis in meningococcal diseases [12]. Bacteria were identified, and serogroups were defined in serum specimens in six patients. Serogroup B was the predominant serogroup in our case series. Even though blood cultures are positive in $40 \%$ to $75 \%$ of cases according to the literature, no growth was detected in any of our patients' blood cultures [13]. Two patients died in our case series, one due to serogroup $B$ and the other due to serogroup W. New hyperinvasive clones of serogroup W have been admitted with severe clinical courses, and the case fatality rate of serogroup $\mathrm{W}$ is higher than that of serogroups $\mathrm{B}$ and $\mathrm{C}[8]$.

$N$. meningitidis has become the most important target agent of vaccine studies after successful implementation of vaccines, resulting in decreased prevalence of the other two most common agents causing meningitis, Haemophilus influenzae tip B, and Streptococcus pneumoniae [14]. None of the patients in our study had been vaccinated with meningococcal vaccines. Immunization against IMD is the best prevention strategy for controlling the disease. In Turkey, quadrivalent conjugated meningococcal vaccines (MenACWY) and meningococcal B vaccine (4CMenB) are available in private practice and are not part of the National Immunization Program. MenACWY vaccines have been routinely used in Hajj and Umrah pilgrimages and also have been used among military personnel [1]. Meningococcal conjugate vaccines and MenB vaccines have been routinely recommended for patients undergoing splenectomy and also patients requiring eculizumab treatment. Seroepidemiology of IMD in Turkey is dynamic and quite different when compared to other countries [14]. Serogroup $B$ is the predominant strain, followed by serogroup W; other serogroups (A, Y, C, and X) have been sporadically reported [14]. IMD and serogroup surveillance are crucial for further vaccine implementation into the National Immunization Program.

Our study has some limitations. This is a retrospective, short-term interval, single-center experience and includes only children requiring PICU. We did not show the serogroup in six out of 12 cases. However, we report 12 cases with IMD from the city with the largest birth cohort, and our study results highlight the severity of the infection among previously healthy children. We underline the importance of early antibiotic treatment accompanied by early and intense supportive therapy in PICU, and these interventions could decrease the predicted mortality rate at admission. Routine use of meningococcal vaccines during childhood would be a better strategy for controlling IMD in both developing and developed countries.

\section{Data Availability}

Access to data is restricted. Data sharing is not possible, as they include retrospective patient records, to protect the privacy of patient data.

\section{Conflicts of Interest}

The authors declare that they have no conflicts of interest.

\section{References}

[1] S. R. Parikh, H. Campbell, S. J. Gray et al., "Epidemiology, clinical presentation, risk factors, intensive care admission and outcomes of invasive meningococcal disease in England, 2010-2015," Vaccine, vol. 36, no. 26, pp. 3876-3881, 2018.

[2] Y. L. Tzeng and D. S. Stephens, "A narrative review of the W, $\mathrm{X}, \mathrm{Y}, \mathrm{E}$, and NG of meningococcal disease: emerging capsular Groups, pathotypes, and global control," Microorganisms, vol. 9, no. 3, p. 519, 2021.

[3] C. Burman, L. Serra, C. Nuttens, J. Presa, P. Balmer, and L. York, "Meningococcal disease in adolescents and young adults: a review of the rationale for prevention through vaccination," Human Vaccines \& Immunotherapeutics, vol. 15, no. 2, pp. 459-469, 2019.

[4] I. Rivero-Calle, L. Vilanova-Trillo, J. Pardo-Seco, L. B. Salvado, L. I. Quinteiro, and F. Martinon-Torres, "The burden of pediatric invasive meningococcal disease in Spain (2008-2013)," Pediatric Infectious Disease Journal, vol. 35, no. 4, pp. 407-413, 2016.

[5] R. C. Brady, "Meningococcal infections in children and adolescents," Advances in Pediatrics, vol. 67, pp. 29-46, 2020.

[6] B. Wang, R. Santoreneos, L. Giles, H. Haji Ali Afzali, and H. Marshall, "Case fatality rates of invasive meningococcal disease by serogroup and age: a systematic review and metaanalysis," Vaccine, vol. 37, no. 21, pp. 2768-2782, 2019.

[7] A. Rhodes, L. E. Evans, W. Alhazzani et al., "Surviving sepsis campaign: international guidelines for management of sepsis and septic shock: 2016," Intensive Care Medicine, vol. 43, no. 3 , pp. 304-377, 2017.

[8] S. Nadel, "Treatment of meningococcal disease," Journal of Adolescent Health, vol. 59, no. 2, pp. S21-S28, 2016.

[9] S. Nadel and N. Ninis, "Invasive meningococcal disease in the vaccine era," Frontiers in Pediatrics, vol. 6, p. 321, 2018.

[10] C. Stein-Zamir, H. Shoob, I. Sokolov, A. Kunbar, N. Abramson, and D. Zimmerman, "The clinical features and long-term sequelae of invasive meningococcal disease in children," Pediatric Infectious Disease Journal, vol. 33, no. 7, pp. 777-779, 2014.

[11] T. Waterfield, M. D. Lyttle, M. D. Lyttle et al., "The "Petechiae in Children" ( $\mathrm{PiC}$ ) study: evaluating potential clinical decision rules for the management of feverish children with nonblanching rashes, including the role of point of care testing for procalcitonin \& neisseria meningitidis DNA-a study protocol,” BMC Pediatrics, vol. 18, no. 1, p. 246, 2018.

[12] S. Guiducci, M. Moriondo, F. Nieddu et al., "Culture and realtime polymerase chain reaction sensitivity in the diagnosis of invasive meningococcal disease: does culture miss less severe cases?" PLoS One, vol. 14, no. 3, Article ID e0212922, 2019.

[13] L. E. Vaz, "Meningococcal disease," Pediatrics in Review, vol. 38, no. 4, pp. 158-169, 2017.

[14] M. Ceyhan, Y. Ozsurekci, S. Tanır Basaranoglu et al., "Multicenter hospital-based prospective surveillance study of bacterial agents causing meningitis and seroprevalence of different serogroups of neisseria meningitidis, haemophilus influenzae type b, and streptococcus pneumoniae during 2015 to 2018 in Turkey," mSphere, vol. 5, no. 2, p. 20, Article ID e00060, 2020. 